\title{
Functional conservation and maintenance of expression pattern of FIDDLEHEAD-like genes in Arabidopsis and Antirrhinum
}

\author{
Nadia Efremova ${ }^{1}$, Lukas Schreiber ${ }^{2}$, Sascha Bär ${ }^{1}$, Iris Heidmann ${ }^{1}$, Peter Huijser ${ }^{1}$, \\ Kirsten Wellesen ${ }^{1}$, Zsuzsanna Schwarz-Sommer ${ }^{1}$, Heinz Saedler ${ }^{1}$ and Alexander \\ Yephremov $^{1, *}$ \\ ${ }^{1}$ Max-Planck-Institut für Züchtungsforschung, Carl-von-Linné-Weg 10, 50829 Köln, Germany (*author for \\ correspondence; e-mail efremov@mpiz-koeln.mpg.de); ${ }^{2}$ Institut für Zelluläre and Molekulare Botanik, Uni- \\ versität Bonn, Kirschallee 1, D-53115 Bonn, Germany
}

Received 14 June 2004; accepted in revised form 28 October 2004

Key words: ANTIRRHINUM FIDDLEHEAD, chemical genetics, epidermis, fatty acid elongases, ovary septum

\begin{abstract}
In Arabidopsis, loss of function of the epidermis-specific $F D H$ gene coding for a putative $\beta$-ketoacyl-CoA synthase results in ectopic organ fusions in mutants. Corresponding mutants are not available for Antirrhinum majus, however, organ fusions can be induced in both species by chloroacetamide inhibitors of $\beta$-ketoacyl-CoA synthases using a chemical genetics approach. We isolated the ortholog of $F D H$ from Antirrhinum majus, the ANTIRRHINUM FIDDLEHEAD (AFI) gene, and showed that AFI complements $f d h$ when expressed in the epidermis under control of the $F D H$ promoter. Like $F D H$, the $A F I$ gene exhibits protodermis- and epidermis-specific expression, and its promoter directs the expression of reporter genes to the epidermis in transgenic Antirrhinum and Arabidopsis. We demonstrate down-regulation of the $F D H$ promoter in the epidermis of the ovary septum, thereby supporting the assumption that $F D H$-like genes may directly facilitate the cell-cell interactions that need to occur during carpel fusion and pollen tube growth. Up-regulation of $F D H$ in the stomium, on the other hand, provides evidence for its possible involvement in cell separation during anther dehiscence. Down-regulation of the FDH and AFI promoters in the septum is observed in transgenic Arabidopsis but not in Antirrhinum plants. This probably reflects differences in the ontogeny of the ovary septum between the two species. We also show that epidermis-specific $F D H$-like genes may not be able to efficiently elongate fatty acid chains when misexpressed in seeds.
\end{abstract}

\section{Introduction}

The epidermis is a composite tissue that forms the outer layers of plant organs, and is specialized for protection of other tissues against unfavorable environmental factors, and regulates gas and water exchange. It also plays a critical role in the partitioning of organs during development and in controlling cell-cell interactions during the fertilization process. Epidermal cells exhibit polarity; their outermost cell walls appear to be thicker than adjoining cell walls and deposit the cuticle and waxy lipids onto the exposed surface.

During ontogenesis, all epidermal cells originate from the exterior single-cell layer of meristems (denoted L1), where cells generally divide anticlinally. In meristems, undifferentiated epidermal cells make up the protodermis, which then undergoes differentiation to give rise to the various cell types of the epidermis. Orchestration of a number of pathways and cell-cell communication are necessary for proper differentiation of 
protodermal cells (Van Den Berg et al., 1997; Huelskamp and Schnittger, 1998). In Arabidopsis, studies on the FIDDLEHEAD (FDH), HIGH CARBON DIOXIDE (HIC), LACERATA (LCR) and WAX2/YORE-YORE genes have revealed a role for fatty acid metabolism in this process (Yephremov et al., 1999; Pruitt et al., 2000; Wellesen, 2001; Chen et al., 2003; Kurata et al., 2003). The $F D H$ and $H I C$ genes code for putative $\beta$-ketoacylCoA synthases of the FATTY ACID ELONGATIONI (FAEI) gene family, which consists of 21 genes in Arabidopsis (Lechelt-Kunze et al., 2003).

The epidermis-specific $F D H$ gene is implicated in the control of a barrier function associated with the outermost cell walls of the epidermis (Lolle et al., 1997; Yephremov et al., 1999; Pruitt et al., 2000). Suppression of this function in $f d h$ mutants results in ectopic organ fusions, and allows wildtype pollen to germinate on the leaf epidermis of fdh mutants (Lolle et al., 1992; Lolle and Cheung, 1993). Mutations in FDH also compromise the differentiation of trichomes (Yephremov et al., 1999).

Sequences homologous to FDH are known to be present in genomes of different plants species, suggesting that they share a common function, but this has not been investigated.

Here we describe isolation of the ANTIRRHINUM FIDDLEHEAD (AFI) gene from Antirrhinum majus and shows that, based on the similarities in their coding sequences and genomic organization, $F D H$ and $A F I$ comprise a pair of orthologous genes. Mutants at the AFI locus are not available, however, organ fusions can be chemically induced in both species by chloroacetamide inhibitors of $\beta$-ketoacyl-CoA synthases. Furthermore, based on the complementation experiment with the $f d h$ mutant, we show that the biochemical functions of FDH and AFI are similar.

Investigating the expression of organ fusion genes in the ovary epidermis is imperative to understanding whether a common pathway controls epidermal fusions of various organs in plants. In this paper, we demonstrate the down-regulation of the FDH promoter in the ovary septum epidermis supporting an idea that $F D H$ plays a role in controlling carpel fusion and assisting pollen interactions in Arabidopsis (Lolle et al., 1992; Lolle and Cheung, 1993). Then, we demonstrate protodermis- and epidermis-specific activity of the
$F D H$ and $A F I$ promoters in reciprocally transformed Arabidopsis and Antirrhinum plants. Common transcriptional regulation of $F D H$-like genes is further indicated by the fact that in the ovary septum of transgenic Arabidopsis plants, the AFI promoter behaves similarly.

\section{Materials and methods}

\section{Plant material}

Antirrhinum majus and Arabidopsis thaliana ecotype Columbia $(\mathrm{Col})$ were grown in the greenhouse at $18-23{ }^{\circ} \mathrm{C}$ or in growth chambers at $16-21{ }^{\circ} \mathrm{C}$ under $16 \mathrm{~h}$ of light. The wild-type Antirrhinum line $165 \mathrm{E}$ is a derivative of the line niv-98 (John Innes Centre Collection, Norwich, UK). The L1 def periclinal chimera in the $165 \mathrm{E}$ genetic background is from our own strain collection (Perbal et al., 1996).

Derivation of an Arabidopsis line carrying the transposon footprint $f d h-3940 S 1$ allele has been described previously (Yephremov et al., 1999).

\section{Nucleic acid techniques}

Basic nucleic acid techniques were performed as described previously (Yephremov et al., 1999). DNA fragments used for vector construction were amplified with Pfu polymerase (Stratagene) or the Expand High Fidelity PCR System (Roche Molecular Biochemicals).

\section{Cloning of the FDH, AFI, and FAE1 promoters}

Recombinant clones were isolated from an Arabidopsis genomic library (J. Mulligan and R. Davis, Stanford University). Two primers, PF1021 (AAACAAGCTTAAGTCTACAACAATTAGC GTC) containing a HindIII recognition site (added restriction sites are underlined), and $\mathrm{PF} 21 \mathrm{Xb}$ (TTTTTCTAGAGTAGGTTGATTATGTGAG TGAG) containing a $X b a \mathrm{I}$ restriction sites, were used for PCR amplification of the 1122-bp FDH promoter fragment.

Antirrhinum cDNA and genomic libraries were kindly provided by H. Sommer, Max-PlanckInstitut für Züchtungsforschung (MPIZ). For the isolation of $A F I \mathrm{cDNA}$, hybridization with a $F D H$ 
cDNA probe was performed at $54{ }^{\circ} \mathrm{C}$. For cloning, AFI cDNA was amplified with AFI-Xba (AAAAAATCTAGATTGTGCGACAAAATTT TGTACTCA) and AFI-XbaR (GTAAATTTTC TAGACCCATCTTAGTGTTTCCATC) primers. The orientation of $A F I$ in recombinant genomic clones was determined by PCR using all possible combinations of the left-arm phage primer E3L1 (GCGTACTGACGGATTCATCGTTG) and the right-arm phage primer E3R2 (ATATGCTTT CCATTCCATCGGG) with the AFI primers i3 (GCAAGAAAATCCGGAAAATTCAC) and i4 (CTCGGTTTGTAGCACGCAAAATC). To amplify the 1460-bp $A F I$ promoter fragment, the primers AN-H (AAAGCTTACTTTCGTAAT CATATTACCCAACCG) and AN-X (TTCT AGAGTTGTTTGGTTTGAGGATTGAGATGA) were used (HindIII and $\mathrm{XbaI}$ sites are underlined). A pBluescript KS derivative, carrying this fragment in direct orientation with respect to $\operatorname{lac} Z$, was named pBSPAF.

The 1185-bp FAE1 promoter fragment was obtained by PCR with the FAE-X (AAAATCT AGATCCGTTACGTTTTACAAAGC) and FAEH (AAAAAAGCTTCCTAATACGACTCACTA TAG) primers.

Construction of binary vectors and transformation of plants

Two series of binary vectors, $\mathrm{pB}$ and $\mathrm{pH}$ types, carrying a phosphinothricin $N$-acetyltransferase (BAR) or a hygromycin phosphotransferase gene (HPT), respectively, were similarly constructed from pGPTV-BAR or pGPTV-HYG (Becker et al., 1992) as follows.

The $X b a \mathrm{I} / S a c \mathrm{I}$ fragment containing the $\beta$-glucuronidase reporter gene (GUS) from pGPTVBAR was replaced by an $X b a \mathrm{I} / S a c \mathrm{I}$ fragment containing either the GUS-INT reporter gene from p35S GUS INT (Vancanneyt et al., 1990) or a green fluorescent protein reporter gene (GFP) from pBIN m-gfp5-ER (Haseloff and Siemering, 1998). This resulted in the pBgint or pBgreen binary vector, respectively. A HindIII/XbaI fragment of 1122 bp carrying the $F D H$ promoter was inserted between the HindIII and $X b a \mathrm{I}$ sites in $\mathrm{pBgint}$ and $\mathrm{pBgreen}$, giving $\mathrm{pBPF}$ gint and $\mathrm{pBPF}-$ green. The $X b a \mathrm{I} / \mathrm{SacI}$ fragments carrying reporter genes in $\mathrm{pBgint}$ and $\mathrm{pBgreen}$ vectors were substituted for polylinkers, which contained unique cloning sites for $X b a \mathrm{I}, B s i \mathrm{WI}, X h o \mathrm{I}, S c a \mathrm{I}, S m a \mathrm{I}$ and $\mathrm{SaCI}$ in that order in the XS polylinker or in the reverse order in the SX polylinker. The binary vectors $\mathrm{pBPF}-\mathrm{XS}$ and $\mathrm{pBPF}-\mathrm{SX}$ constructed in this way allow the expression of a gene of interest from the $F D H$ promoter. In $\mathrm{pH}$-type vectors, pHPFgint and pHPFgreen, the same $F D H$ promoter fragment was similarly inserted upstream of the GUS or GFP gene. FDH promoter deletion constructs were derived from $\mathrm{pBPF}$-XS.

To clone the AFI promoter into binary vectors, pBSPAF (see above) was partially digested with HindIII and completely digested with $X b a \mathrm{I}$. This resulted in two $A F I$ promoter-containing segments - a long fragment containing $1460 \mathrm{bp}$ and a short fragment containing the 470-bp segment extending from the internal HindIII site to the AN-X primer. The long and short segments of the AFI promoter substituted for the $F D H$ promoter in corresponding binary vectors. In total, four $\mathrm{pB}$ - and four $\mathrm{pH}$-type binary vectors were generated with GUS and GFP reporter genes, which allowed comparisons between the activities of the long and short versions of the AFI promoter. The pHAF-XS binary vector was produced in a similar way to pBPF-XS, and contains the XS polylinker downstream of the AFI promoter.

The pBPF-AFI vector used in the transgenic complementation test contained $A F I$ cDNA cloned into pBPF-XS. FDH cDNA was cloned into pBPFAE-XS derived from pBPF-XS by substituting the $F D H$ promoter with the FAE1 promoter, which allows expression of genes in seeds.

Transgenic Antirrhinum and Arabidopsis plants were obtained by transformation using A. tumefaciens, as described (Heidmann, et al., 1998; Yephremov et al., 1999).

\section{$R N A$ in situ hybridization and microscopy}

Preparation of tissues, and in situ hybridization with digoxigenin-labeled RNA probes were done as described (Perbal et al., 1996). For negative control, a sense probe was used to hybridize sections. In addition, control hybridizations were carried out with antisense probes to floral organspecific MADs-box genes (data not shown). Sections were inspected under bright-field illumination using a Zeiss Axiophot microscope. 
Sections of the L1 def chimera were additionally stained with Calcofluor and viewed under fluorescent light using the same microscope.

GFP fluorescence in transgenic plants was examined with a Leica TCS 4D confocal laser scanning microscope using a fluorescein isothiocyanate filter set. For analysis, fresh tissues were mounted in 5\% Small DNA Low Melt Agarose (Biozym) containing $\quad 0.005 \%$ Silwet L-77 (OSi Specialities). Agarose blocks of about $0.5 \times 0.5 \times 1 \mathrm{~cm}$ were mounted on a Leitz 1512 Vibratome stage and sections of $100-150 \mu \mathrm{m}$ were cut.

\section{Histochemical analysis of expression using GUS substrates}

Portions of tissue or whole seedlings were stained for GUS activity with X-Gluc in phosphate buffer according to Jefferson et al. (1987), except that ferrocyanide salts were omitted from the staining solution. Staining with ImaGene Green fluorogenic GUS substrate (Molecular Probes) was performed as recommended in the protocol provided; section preparation and microscopy was carried out as for GFP transgenic plants.

\section{Genotyping of the FDH locus}

DNA has been extracted as described previously (Klimyuk et al., 1993) with modifications that included collecting leaf material in 96-well plates (\#850289, HJ-Bioanalytik, Germany) and crushing with Mixer Mills MM 200 (Retsch, Germany). Following PCR with Taq polymerase (Roche Molecular Biochemicals) with FDH102 (GGTCAGGAGACGTTTGCCTGATTT) and FDH252 (TCTGCTTAAACTCCCAACCTCAGC) primers, the obtained DNA fragments containing the site of the $f d h-3940 S 1$ polymorphism (Yephremov et al., 1999) were analyzed at $61{ }^{\circ} \mathrm{C}$ with an automated DHPLC instrument equipped with a DNASep column (WAVE; Transgenomic, San Jose, CA). Chromatograms characteristic for homoduplexes and heteroduplexes $(\mathrm{FDH} / f d h-3940 S 1)$ were visually identified. Homoduplex and $\mathrm{Col}$ amplicons were mixed in an approximately equimolar ratio, denatured in a thermocycler at $95^{\circ} \mathrm{C}$ for $1 \mathrm{~min}$, followed by 30 cycles, each with a 30 -second annealing step that decreased $1{ }^{\circ} \mathrm{C} /$ cycle. The annealed samples were separated with DHPLC into homoduplexes $(F D H /$ $F D H)$ and heteroduplexes attesting to a mixture of Col with $f d h-3940 S 1 / f d h-3940 S 1$. Representative samples and the samples obtained from complemented mutants were sequenced. To confirm genotyping the progeny of complemented mutants were similarly analyzed.

\section{Fatty acid composition analysis}

Between 1 and $2 \mathrm{mg}$ of seeds weighted on a microbalance were transesterified for $2 \mathrm{~h}$ at $80^{\circ} \mathrm{C}$ in $1 \mathrm{M} \mathrm{HCl}$ in methanol. After cooling, the samples were extracted three times with hexane containing $20 \mu \mathrm{g}$ tetracosane (Fluka) as internal standard. The combined hexane extracts were evaporated under a gentle stream of nitrogen and the residue was derivatized at $73{ }^{\circ} \mathrm{C}$ using BSTFA ( $N, N$-bis-trimethylsilyltrifluoroacetamide; Machery-Nagel, Germany) catalyzed with pyridine to convert free hydroxyl and carboxyl groups to their respective trimethylsilyl esters and ethers. Samples were redissolved in chloroform, and gas chromatography coupled to mass spectroscopy (6890N gas chromatograph and 5973 NA mass selective detector from Hewlett-Packard/Agilent Technologies) was used for identification and quantification of the methyl esters of primary fatty acids released from the seeds.

Nonparametrical data analysis was performed using STATISTICA 6.0 package from the StatSoft (Tulsa, OK).

\section{Chemical treatments of plants}

Water solutions $(0.005-0.015 \%)$ for spraying plants were prepared from $10 \%$ stock solutions of alachlor, acetochlor, butachlor, and metolachlor (Supelco, Deisenhofen, Germany) in methanol. Arabidopsis and Antirrhinum plants were sprayed at the age of 3-4 weeks, and symptoms of inhibition of the $\beta$-ketoacyl-CoA synthase activity were recorded a week later.

\section{Phylogenetic analysis}

Analysis of gene relationships in the FAE1 family was accomplished by first generating a multiple protein sequence alignment (available from the authors upon request) using the PILEUP program from the Genetics Computer Group (Madi- 
son, WI) software package. Further phylogenetic analysis was performed using programs in the PHYLIP package (v.3.573, http://evolution.genetics.washington.edu/phylip.html). The sequence alignment was subjected to bootstrapping for 1000 replications using the SEQBOOT program, and the dataset was analyzed using the PROTDIST program with the PAM250 model. The resulting distance matrices were further analyzed using the NEIGHBOR program, applying the neighbor-joining algorithm with randomization of the input order. The consensus tree was generated using the CONSENSE program.

\section{Results}

\section{Isolation of the AFI gene of Antirrhinum majus}

It may be anticipated that, like the $F D H$ gene, its ortholog in Antirrhinum will be abundantly expressed in the epidermis of developing floral organs. Therefore, an Antirrhinum cDNA library prepared from floral buds $(2-10 \mathrm{~mm})$ was used for gene isolation. After screening with a $F D H$ cDNA probe at low stringency (see Materials and methods), 12 positive clones were selected and analyzed by sequencing. All clones represented cDNAs derived from a single gene, which was named ANTIRRHINUM FIDDLEHEAD (AFI). Its open reading frame encodes 541 amino acids, and the deduced protein sequence displays a high level of similarity to that of FDH (see below). The $A F I$ cDNA hybridized to unique fragments on genomic DNA blots (data not shown) and to a set of overlapping genomic clones comprising the $A F I$ gene (GenBank Accession No.AJ310739). Comparison of cDNA and genomic sequences revealed that, like $F D H$, the $A F I$ gene contains two introns of 900 and $200 \mathrm{bp}$.

\section{AFI is most closely related to Arabidopsis FDH, as revealed by coding sequence similarity and gene structure}

The FDH gene belongs to the FAE1 family, the members of which encode known and putative $\beta$-ketoacyl-CoA synthases expressed during seed development and in the epidermis (Yephremov et al., 1999; Pruitt et al., 2000). This plant gene family contains multiple sequences, including 21 predicted proteins encoded in the complete Arabidopsis genome (Lechelt-Kunze et al., 2003). Computerized searches using the BLAST program (http://www.ncbi.nlm.nih.gov/BLAST/) revealed that the sequence of the AFI protein is most similar to $\mathrm{FDH}$, giving $82 \%$ homology and $72 \%$ identity. The corresponding scores for other Arabidopsis members of the FAE1 family were significantly lower $-73-58$ and 55-35\%, respectively.

In order to quantify the degree of similarity between the currently known genes of the FAE1 family, we constructed multiple alignments of protein sequences and analyzed them further using programs in the PHYLIP package. The phylogenetic analysis indicated that $A F I, F D H$ and GhFDH, a gene from Gossypium hirsutum (GenBank Accession No. AAL67993) form a discrete monophyletic group derived from a common ancestral sequence that predates the divergence of these species (Figure 1). This conclusion, based on sequence similarity, is supported by the intron distribution in the FAE1 family. The combination of two introns found in the $A F I$ and $F D H$ genes is not observed elsewhere in the family and is probably inherited from the ancestral gene. The gene encoding the At3g52160 protein shows the highest sequence similarity to the FDH group. It is characterized by a single intron that appears in the same position as the first intron in $F D H$ and $A F I$ (Figure 1). Taken together, the results obtained by both methods agree in implying that these proteins are closely related.

Intron distribution analysis can also be productive in elucidating the phylogeny of two other groups within the FAE1 family, which are characterized by the presence of single introns in specific positions. One comprises the genes encoding the CUT1/CER6 and CER60 proteins, and the other is made up of the genes encoding the At1g04220 and At5g43760 proteins (Figure 1). As with most fatty acid elongases, the lack of expression and biochemical data makes it difficult to probe these relationships further.

\section{Misexpression of the epidermis-specific FDH gene in seeds}

Biochemical functions of most members of the FAE1 gene family are currently unknown.

If FDH and AFI are $\beta$-ketoacyl-CoA synthases as it follows from their sequence similarity, they 


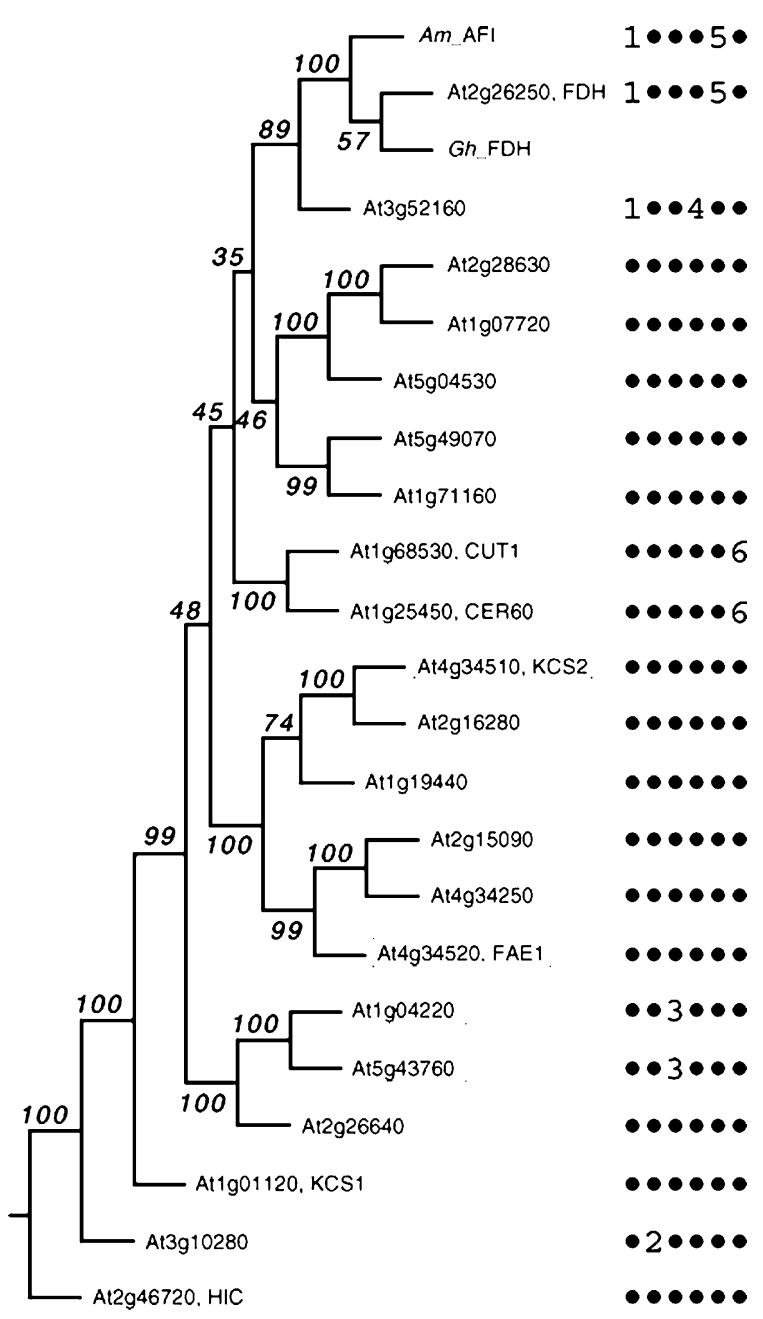

Figure 1. Phylogenetic position of the FDH-like genes in the FAE1 gene family. The consensus phylogenetic tree for deduced amino acid sequences was obtained with bootstrapping for 1000 replications; the numbers at each fork indicate the frequencies $(\%)$ with which the group consisting of the species to the right of the fork was recovered. Lengths of horizontal branches are proportional to distances. Protein sequences were obtained from GenBank and are indicated by AGI (Arabidopsis Genome Initiative) gene codes and gene names if known. Available exon-intron structures of genes are depicted to the right of the tree. Introns were numbered according to their positions in the multiple protein alignment (the alignment file is available upon request). Names of proteins capable of elongating very long chain fatty acids (VLCFA) are boxed. At, Arabidopsis thaliana; Am, Antirrhinum majus; Gh, Gossypium hirsutum.

could be active when plants were made to misexpress them in seeds. We performed promoter swapping experiments, in which $F D H$ was driven by the $F A E 1$ promoter of a seed-specific $\beta$-ketoacyl-CoA synthase (James et al., 1995; Rossak et al., 2001). Transgenic plants were not
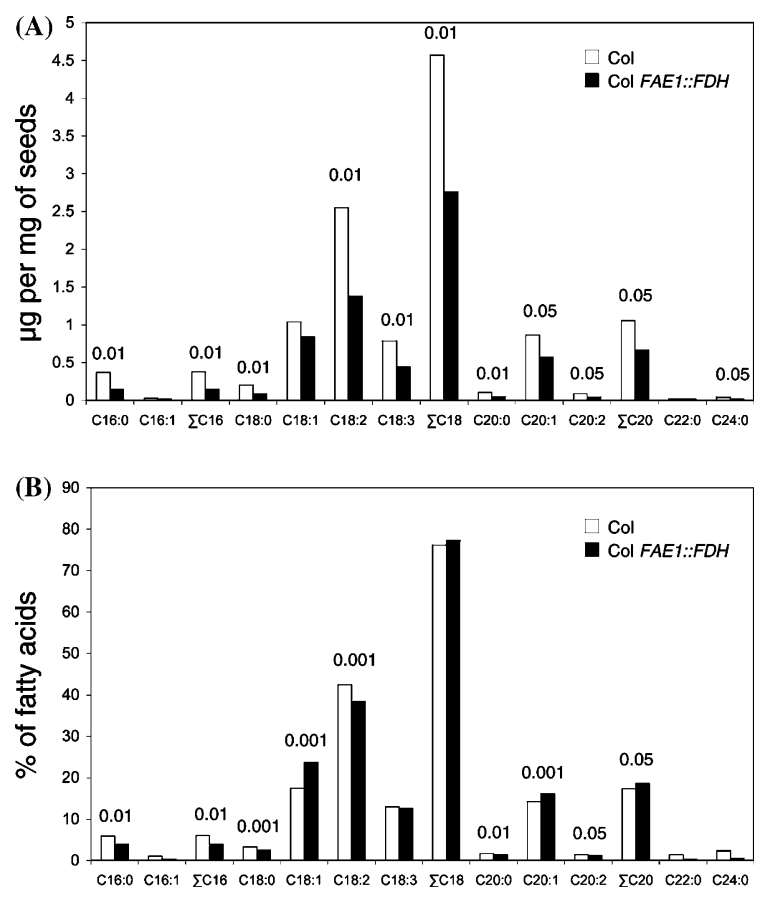

Figure 2. Comparison of the fatty acid composition of wildtype Arabidopsis and transgenic FAE1::FDH seeds. Thirty-two transgenic lines were randomized into eight equal samples, each of 150-200 seeds, and compared to eight wild-type samples. Fatty acids were extracted and analyzed by GC-MS. The level of individual fatty acids is expressed as the amount per $\mathrm{mg}$ of seeds (A) and a percentage (B). $p$ values calculated by nonparametcal Wilcoxon-Mann-Whitney test are depicted above bars if they are $\leq 0.05$.

phenotypically different from wild-type plants, but results of fatty acid composition analysis show that FAE1::FDH transgenic $\mathrm{T}_{2}$ seeds generally accumulate $40 \%$ less fatty acids in oil than wildtype seeds (Figure 2A). Relatively more C18 and $\mathrm{C} 20$ fatty acids in expense of C16s were accumulated in transgenic seeds, suggesting increasing elongation of fatty acids (Figure 2B). Also, the C18/C16 and C20/C16 VLCFA product ratios have been increased in transgenic seeds to 20.8 and 5.1 from 13.3 and 3.0 in the wild types, respectively, However, further experiments are required to confirm that these changes can be directly attributed to the enzymatic action of the FDH protein and not to a metabolic response.

\section{AFI is able to complement the fdh mutation}

The AFI gene was examined for its ability to complement $f d h$. Because the $f d h$ mutant is 

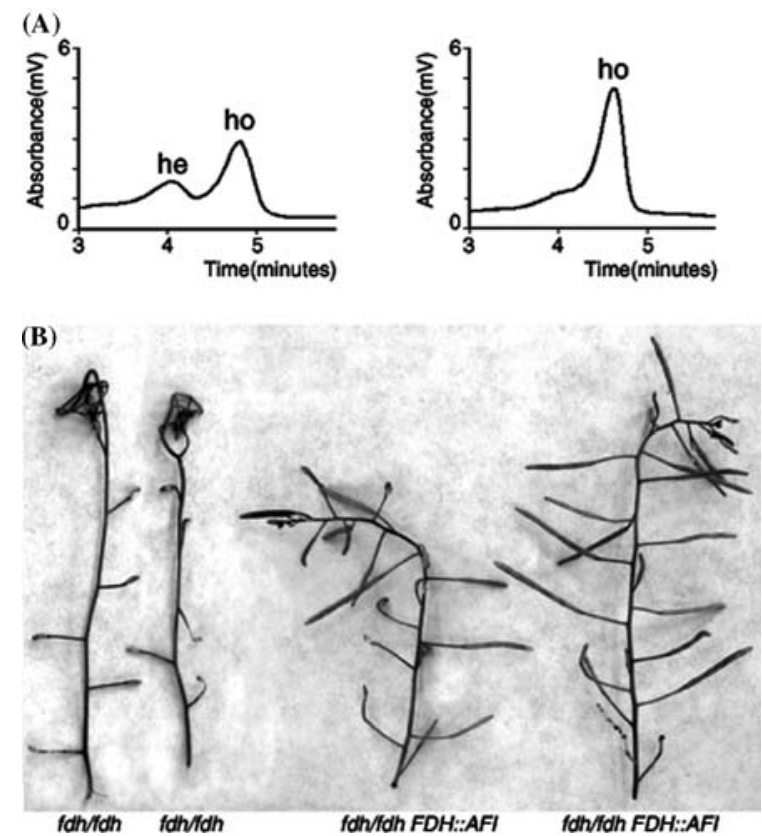

Figure 3. Transgenic complementation of the $f d h$ mutant with the $A F I$ gene. (A). Detection of the $f d h 3940 S 1$ allele carrying a 2-bp insertion by separating heteroduplex (he) and homoduplex (ho) 151-bp DNA fragments with DHPLC (see Materials and methods). Retention time is plotted against intensity of the signal in millivolts $(\mathrm{mV})$. (B). Sterile shoots of $f d h$ showing typical floral fusions and fertile shoots of $f d h$ complemented with $F D H:: A F I$.

sterile, complementation analysis was performed with using segregating progeny of $F D H /$ fdh3940S1 heterozygotes $\left(\mathrm{T}_{0}\right)$ transformed with a $F D H:: A F I$ transcriptional fusion construct. $\mathrm{T}_{1}$ transformants have been genotyped, and seeds of several independent $\mathrm{T}_{1} \quad F D H / f d h 3940 S 1$ $F D H:: A F I$ plants have been collected. With $\mathrm{T}_{2}$ plants, three kinds of analysis were performed. First, plants were segregated into the $f d h$ and wild type phenotypic classes; second, the presence of transgene was validated with PCR; third, genotyping of the $F D H$ locus was done using the Transgenomic WAVE DHPLC system (Figure 3). Among $\mathrm{T}_{2}$ wild types, five fdh3940S1/ fdh3940S1 FDH::AFI plants have been found. Three plants, each derived from a distinct $\mathrm{T}_{0}$ family, were taken for further analysis. They stably transmitted the wild type phenotype to the successive generation corroborating that full complementation of the $f d h$ mutation could be achieved with the $A F I$ gene driven by the $F D H$ promoter.
Chemical genetics: chemically induced fiddleheads in Antirrhinum

Phenocopies of the fiddlehead mutant organ fusion phenotype can be induced by treatment with with low concentrations of herbicides inhibiting $\beta$-ketoacyl-CoA synthases (Lechelt-Kunze et al., 2003; A.Y., unpublished data) or multifunctional acetyl-CoA carboxylase (ACCase) that catalyses the formation of malonyl-CoA from acetyl-CoA (Baud et al., 2004). Because our attempts to identify transposon insertion mutations in the $A F I$ gene have been unsuccessful to date (data not shown), we applied the chemical-genetic approach to test whether the fiddlehead phenotype could be mimicked in Antirrhinum as in Arabidopsis. All four chloroacetamide inhibitors of $\beta$-ketoacyl-CoA synthases (Boeger et al., 2000), acetochlor [2-chloro- $N$-(ethoxymethyl)- $N$-(2-ethyl6-methyl-phenyl)-acetamide], alachlor [ $N$-(methoxymethyl)-2-chloro- $N$-(2,6-diethyl-phenyl)acetamide], butachlor [ $N$-(butoxymethyl)-2-chloro- $N$ (2,6-diethyl-phenyl)acetamide], and metolachlor [2-chloro- $N$-(2-ethyl-6-methylphenyl)- $N$-(2-methoxy-1-methylethyl) acetamide] were capable of inducing the organ fusion phenotype resembling fiddlehead (Figure 4). This supports an idea that a functional equivalent of the $F D H$ gene exists in Antirrhinum.

\section{Localization of AFI mRNA in the epidermis in Antirrhinum}

If $A F I$ represents a functional equivalent of $F D H$, the two genes should display comparable expression patterns. To thoroughly test this, we performed mRNA in situ hybridization using an $A F I$ probe on wild-type Antirrhinum. Indeed, $A F I$ is specifically expressed in the epidermis of various vegetative organs and inflorescences (Figure 5A, $\mathrm{B}, \mathrm{E}-\mathrm{I})$. Strong expression of $A F I$ was observed in reproductive meristems and actively growing organs, as for $F D H$ in Arabidopsis (Yephremov et al., 1999). In flowers, $A F I$ mRNA appears in the epidermis of all floral organs, but its expression declines as organs cease growing. Pre-fusion carpels display $A F I$ expression in adaxial and abaxial epidermal cells; at this stage, cells on the adaxial side of the style cylinder show weaker expression (Figure 5F). There was no marked difference between inner and outer carpel walls in the ovary 

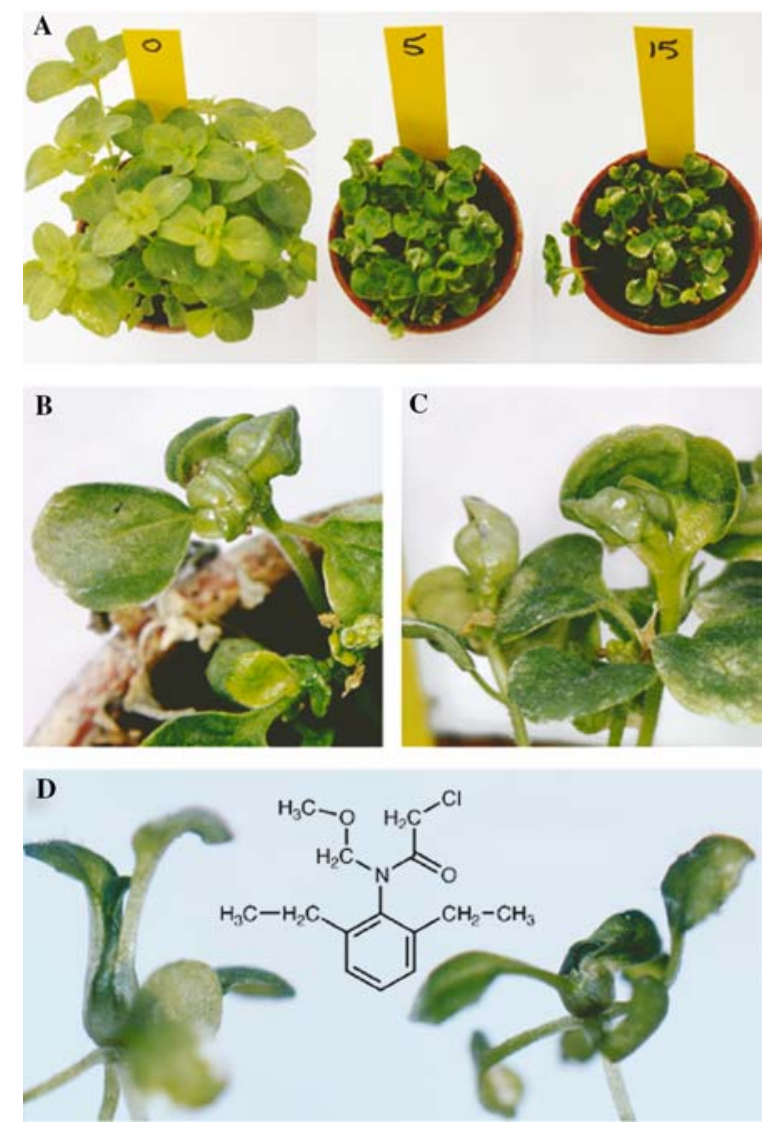

Figure 4. Chemical genetics of FIDDLEHEAD-like genes in Antirrhinum and Arabidopsis. (A-C) Antirrhinum and (D) Arabidopsis plants treated with $N$-(methoxymethyl)-2-chloro$N$-(2,6-diethyl-phenyl)acetamide (alachlor), a potent chemical inhibitor of $\beta$-ketoacyl-CoA synthases, exhibit an organ fusion phenotype closely resembling that of $f d h$ (Lolle et al., 1992). Untreated plants are compared a week after treatment to plants sprayed with $0.005 \%$ and $0.015 \%$ solutions in (A). The structural formula of the chemical inhibitor is shown in (D).

(Figure 5G-I). At later stages, the carpel wall epidermis did not show a hybridization signal while the epidermis of developing ovules clearly did (Figure 5I). In contrast to the case in Arabidopsis, no difference in $A F I$ expression is seen between the ovary septum epidermis and the epidermis of the outer carpel wall in Antirrhinum (Figure 5G-I). Like FDH, AFI is expressed in trichomes, which are glandular and multicellular in contrast to the non-glandular unicellular trichomes in Arabidopsis. At earlier stages, AFI is found to be expressed initially in all cells that make up the trichome, but expression persists only in the terminal glandular cells (Figure 5E, arrows).
The signal distribution at the margins of wildtype petals (Figure 5B, E) indicates that $A F I$ expression is confined to the outermost, single-cell layer of the epidermis. To investigate further whether $A F I$ expression is indeed epidermis-specific rather than L1-specific, we carried out in situ hybridization on L1 def periclinal chimeras. In these plants, L1 is formed by wild-type cells which express the homeotic gene DEFICIENS (DEF), while L2 and L3 are composed of def mutant cells; hence, the L1 lineage in petal margins can be delineated by using a $D E F$ probe (Perbal et al., 1996). Hybridization of serial sections with $D E F$ and $A F I$ probes confirmed that $A F I$ specifically marks the epidermis (Figure 5C) and not the L1 lineage, while $D E F$ expression is detectable in all L1-derived cells (Figure 5D).

\section{A cross transformation strategy for the identification of conserved promoter elements}

The data so far indicate that $A F I$ and $F D H$ are functional orthologs in Antirrhinum and Arabidopsis, respectively, showing identical expression specificity. Based on this it should be reasonable to assume that they exploit an evolutionary conserved mechanism to regulate their transcription. This could involve sharing similar sequence motifs in the promoters and using comparable transcription factors for their control.

Our approach for identifying these sequence motifs involves generating all four possible combinations of transgenic plant and promoter-reporter gene fusion. If Arabidopsis transformed with $F D H$ promoter constructs and Antirrhinum transformed with $A F I$ promoter constructs, show similar epidermis-specific expression patterns, one could infer the boundaries of the two promoters. Comparable patterns of expression uncovered in heterologous transgenic plants, when Antirrhinum is transformed with the $F D H$ promoter constructs, and Arabidopsis transformed with the AFI promoter constructs, could suggest that sequence conservation between the two promoters accounted for the coincidence in expression pattern. Once comparison of two promoter sequences reveals motifs that may be required for the epidermis-specific expression of the $F D H$ and $A F I$ promoters, sequence-specific DNA binding proteins could be identified by yeast one-hybrid screening. 

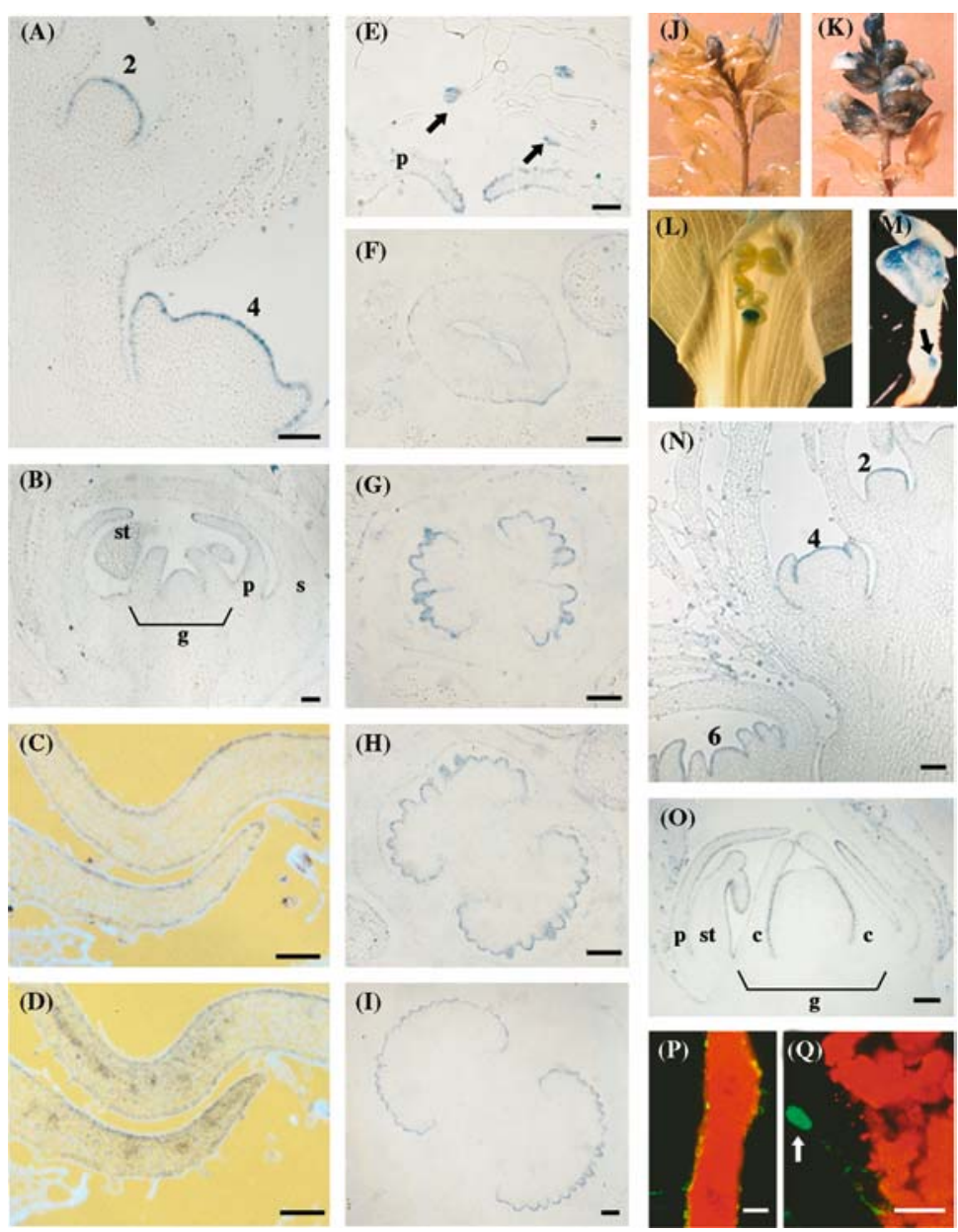

Figure 5. Expression analysis of the AFI gene and its promoter in Antirrhinum plants. In situ hybridization analysis and CLS microscopy of wild-type plants (A, B, E-I, P, Q) and an L1 def chimeric plant of Antirrhinum (C, D). Sections were hybridized with $A F I$ (A-C, E-I), DEF (D) or GUS (N, O) probes. Panels J-O and $\mathrm{P}-\mathrm{Q}$ show details of the expression of the $A F I$ promoter in transgenic $A F I:$ GUS and $A F I::$ GFP plants, respectively. Numbers indicate floral developmental stages (Zachgo et al., 1995); $\mathrm{g}$ - gynoecium, st stamens, $\mathrm{p}$ - petals, $\mathrm{s}$ - sepals, c-carpels. (A). Longitudinal section through an inflorescence apex and two developing floral meristems. Note that expression of $A F I$ in the epidermis is weaker than in the protodermis. (B). Longitudinal section through a developing floral bud.(C, D). Serial sections through petals of a young flower from a L1 def chimeric plant. The hybridization signal in the L1-derived parenchymatous tissues can be seen with a $D E F$ probe (D), while $A F I \mathrm{mRNA}$ is localized exclusively in the epidermis (C). (E). In young wild-type flowers, petal margins display the epidermis-specific $A F I$ signal. Glandular trichome cells (arrows) display a strong signal while the rest of the multicellular trichome does not. (F-I). Pistil cross-sections. The pistil develops as a cylinder comprising two congenitally fused carpels, however, unlike the case in Arabidopsis, postgenital fusion is confined to the style (F). Expression of $A F I$ is more pronounced in the epidermis at the outer wall of carpels. In sections that pass through the ovary $(\mathrm{G}-\mathrm{I})$, the strongest hybridization appears in the epidermis of ovules as they start to develop. Note that despite the similarity in their appearance, the ovary septum in Antirrhinum is ontogenically distinct from the ovary septum in Arabidopsis. J, K. Shoots of AFI::GUS transgenic plants stained with XGluc to display GUS activity. Younger portions of shoots show staining in all organs. (L). Histochemical staining of mature flowers reveals strong GUS expression in the stigma. Some staining is seen in stamens and at the margins of petals. (M). Seedling with stained coleoptiles. A narrow blue strip in the hypocotyl is also visible (arrow). N, O. In situ hybridization analysis with a GUS probe showing that the $A F I$ promoter shows similar activity in inflorescences of $A F I::$ GUS plants to $A F I$ in the wild-type Antirrhinum (compare to A and B). As in G, H and I, the ovule epidermis expresses higher levels of the reporter than the epidermis of other floral organs. P, Q. Confocal laser scanning (CLS; see Materials and methods) microscopy analysis of GFP in AFI::GFP transgenic plants of Antirrhinum. Note GFP expression (green color) in the leaf epidermis (P) and in the trichome (Q). The glandular trichome cell displays high $A F I$ promoter activity $(\mathrm{Q})$, in agreement with in situ hybridization data (E). The red color is due to background fluorescence. Size bars are $100 \mu \mathrm{m}$. 
The phylogenetic-footprinting approach (Duret and Bucher, 1997) described here is based on the assumption that sequence patterns which appear unchanged in orthologous promoters, mutational 'cold spots,' represent the result of selection during the diversification of Arabidopsis and Antirrhinum. The use of site-directed mutagenesis may be required further to define what sequence alterations are compatible with maintenance of epidermis-specific expression in both genes.

\section{Analysis of the AFI promoter in transgenic Antirrhinum plants}

To define the AFI promoter, 1460-bp (Efremova et al., 2001) and 470-bp fragments from upstream of the $A F I$ coding sequence were fused to GFP and $G U S$ marker genes in binary vectors. After transformation of Antirrhinum, several independent transgenic $A F I:: G F P$ and $A F I:: G U S$ plants were obtained with each combination of promoter fragments.

Histochemical analysis of GUS expression, using X-Gluc as the substrate, revealed a noticeable staining gradient within plants (Figure 5J, K), attesting that the $A F I$ promoter was active in growing tissues. In young flowers, GUS activity was detected in all floral organs (Figure 5J, K), however, only the tips of sepals and petals, stamens and the stigma were stained in mature flowers (Figure 5L). Staining was observed in cotyledons and the hypocotyls of seedlings in selfpollinated progeny of $\mathrm{T}_{0}$ transgenic plants; no GUS expression was observed in roots (Figure $5 \mathrm{M})$.

To investigate the tissue specificity of the $A F I$ promoter more precisely, $A F I:$ GUS transgenic plants were analyzed by RNA in situ hybridization with a GUS probe (Figure 5N, O). The hybridization signal was observed exclusively in the L1 layer of the floral meristem and in the epidermis of all floral organs. GUS transcription was found in floral buds starting from stage 1; the signal appeared to be weaker or was undetectable in mature floral organs.

In accordance with the results obtained with the $G U S$ reporter gene, transgenic Antirrhinum plants bearing the $A F I:: G F P$ fusion displayed expression of green fluorescent protein (GFP) in epidermal cells in vegetative organs (Figure $5 \mathrm{P}, \mathrm{Q}$ ).
The long (Efremova et al., 2001) and short $A F I$ promoter fragments drove identical patterns of epidermis-specific expression, and this pattern was similar to that found for the endogenous $A F I$ gene. We, therefore, concluded that the 470-bp $A F I$ promoter fragment carries all the regulatory elements required to control tissue-specific expression.

\section{Analysis of the FDH promoter in transgenic Arabidopsis plants using GFP}

Using in situ hybridization, $F D H$ transcripts have been detected in protodermis cells and in the epidermis of vegetative organs and floral organs, including carpels prior to fusion (Yephremov et al., 1999) and ovules (Pruitt et al., 2000). To investigate the regulatory DNA sequences in the $F D H$ promoter, a 1122 -bp region upstream of the $F D H$ coding sequence was fused to GFP, and its expression was studied in 11 independent families of transgenic plants. GFP fluorescence was detected exclusively in the epidermis of various organs of the transgenic plants (Figure 6). There was no indication of the expression of $F D H$ in phloem or other nonepidermal cells, conversely to what has been reported previously (Pruitt et al., 2000). The expression pattern was equivalent to that revealed by in situ hybridization with a $F D H$ probe in wild-type Arabidopsis (Yephremov et al., 1999), confirming that the promoter fragment carried all cis-acting elements required for normal expression. A stronger GFP signal was observed in the protodermis and in the epidermis of developing organs than in mature organs. Various cell types in the epidermis, e.g. trichomes, displayed GFP expression. Signal distribution was not always uniform among cells; in particular, cell files showing elevated expression were noted in the pistil epidermis (Figure $6 \mathrm{~N}$ ).

In contrast to the obvious activity of $F D H$ in pre-fusion carpels (Yephremov et al., 1999), a conspicuous decline in the GFP signal in $F D H::$ GFP plants was observed following carpel fusion in the epidermis of the ovary septum that divides the pistil into two locules, and in the proximal part of the funiculus (Figure 6E-J). Remarkably, the distal part of the funiculus and the ovule itself both revealed GFP expression (Figure $6 \mathrm{~K}-\mathrm{M}$ ). No activity of the $F D H$ promoter could be detected in epidermal cells that redifferentiated into parenchymatous cells along the 
medial suture resulting from the postgenital fusion in the septum (Figure 6E-H).

In order to delimit the region that is essential for controlling this expression pattern, we produced transgenic Arabidopsis plants carrying shorter fragments of the $F D H$ promoter. Deletion of up to $780 \mathrm{bp}$ at the $5^{\prime}$ end did not affect the tissue-specific expression pattern, while deletion of $1005 \mathrm{bp}$ abolished expression (data not shown). These experiments thus define a 225-bp portion of
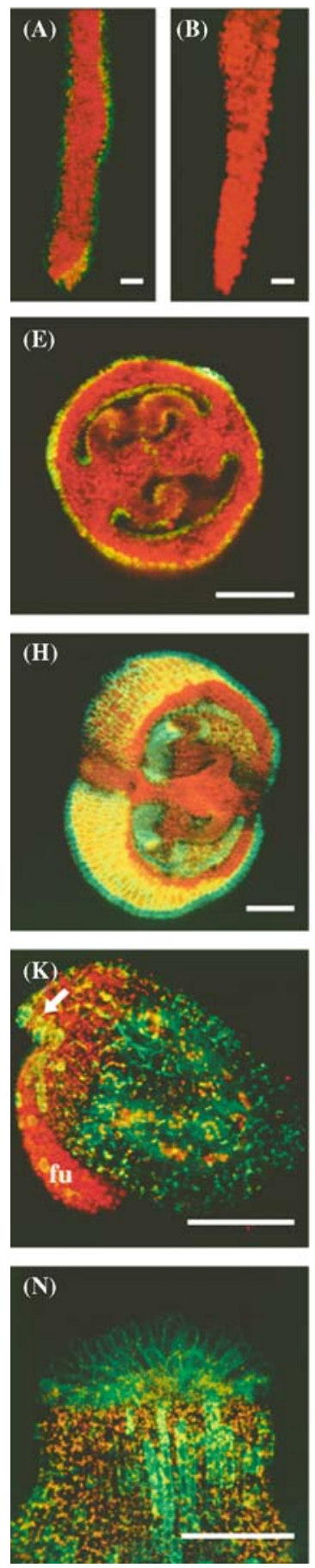
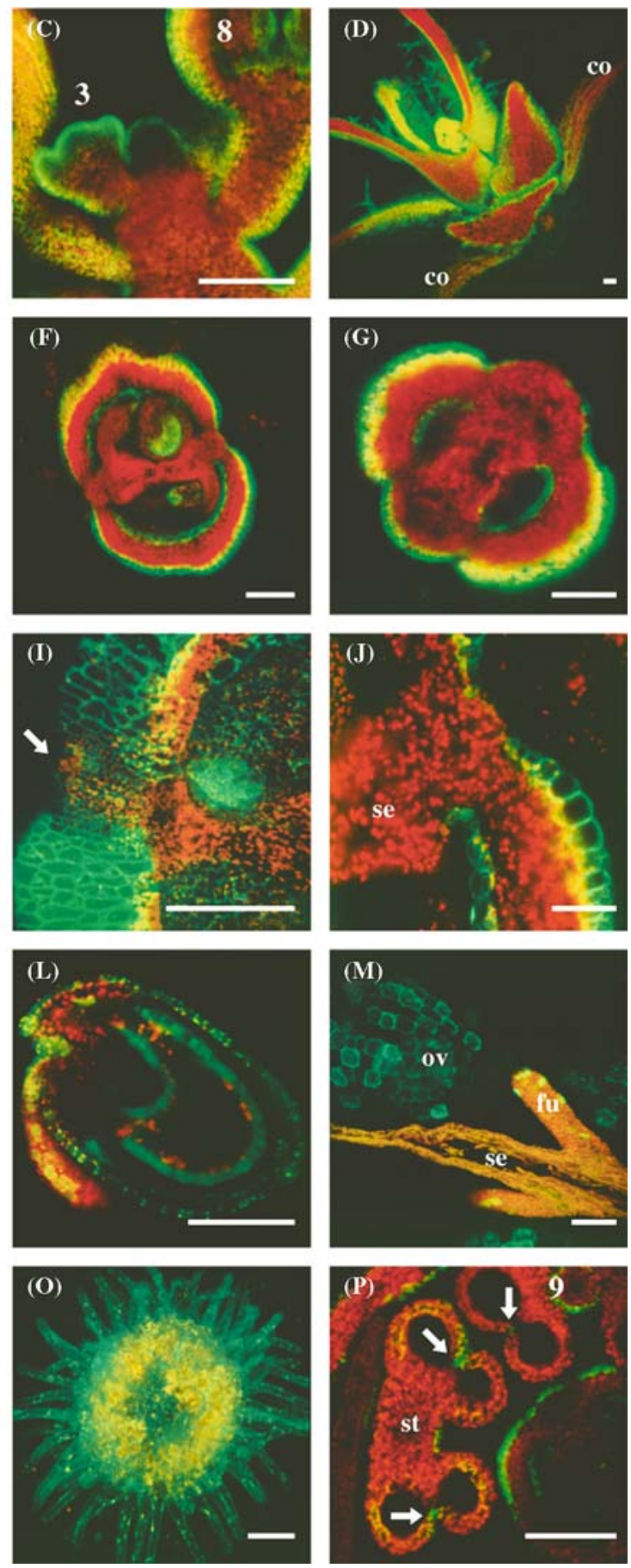
Figure 6. Epidermis-specific expression of GFP under the control of the $F D H$ promoter in vegetative and generative organs of transgenic Arabidopsis. Sections were analyzed using CLS microscopy. Green corresponds to the GFP signal, red to background fluorescence. Numbers indicate floral developmental stages (Smyth et al., 1990). (A, B). Leaves of a transgenic plant (A) and a wild-type plant (B) as a negative control. (C). GFP expression in the protodermis of floral meristems and the epidermis of the inflorescence apex. (D). Young plant having six leaves; note the strong expression in trichomes and the relatively weak expression in cotyledons (co). (E-G). Crosssections of pistils showing $F D H$ promoter-driven expression in the epidermis. Note that the GFP signal declines in the septum but is strong in ovules $(\mathrm{F})$. (H, I). Three-dimensional reconstruction obtained by superimposing pistil cross-sections. Note the relative lack of GFP signal not only in the septum but also in the outer epidermis covering the suture formed by congenitally fused carpels (arrow). (I) shows a portion of $\mathrm{H}$ at higher magnification. (J). Cross-section through the pistil revealing the sharp decline of the GFP signal in the septum (se). Note that localization of the version of GFP used (Haseloff and Siemering, 1998) to the endoplasmatic reticulum allows unambiguous identification of expressing cells due to the circular pattern of signal distribution. (K). Surface of a mature ovule demonstrating GFP expression in a part of the outer integument distal to the micropyle (arrow). The funiculus (fu) and the micropylar part of the ovule essentially lack the GFP signal. Note also that micropyle boundary cells do express the reporter. (L). Optical section of the same ovule as in $(\mathrm{K})$ demonstrating expression in the inner and outer integuments. (M). Septum (se) and funiculus (fu) do not display GFP expression, which is clearly visible in the ovule (ov). (N). Stigmatic part of a pistil demonstrating expression in maturing papilla cells. Note clusters of cells in the style epidermis showing much stronger expression. (O). GFP expression in mature papilla cells as viewed from the top. $(\mathrm{P})$. Cross-section of a mature flower. Note the relatively strong signal in the stomium cells (arrow) in stamens. Size bars indicate $100 \mu \mathrm{m}$ in $\mathrm{A}-\mathrm{I}$ and $\mathrm{K}-\mathrm{P}$, and $25 \mu \mathrm{m}$ in $\mathrm{J}$.

the promoter as being required for epidermis-specific expression.

The FDH and AFI promoters are specifically active in the epidermis in transgenic plants of the heterologous species

We performed reciprocal transformations of heterologous host plants - Antirrhinum was transformed with the $F D H$ promoter fusion constructs, and Arabidopsis with fusion constructs carrying the $A F I$ promoter.

The single $F D H::$ GUS transgenic plant of Antirrhinum that was regenerated carried four independent copies of transgene (data not shown). It displayed expression of the reporter gene in developing floral and vegetative organs (Figure 7A), similar to that observed in the $A F I::$ GUS transgenic Antirrhinum plants (Figure 5J). When the transgenic $F D H::$ GUS Antirrhinum plant was analyzed by in situ hybridization with a GUS probe, no signals could be detected outside the epidermis (Figure 7B, C). The observed pattern of expression was maintained in $F_{1}$ progeny of a cross between the original transformant and the wild-type parent.
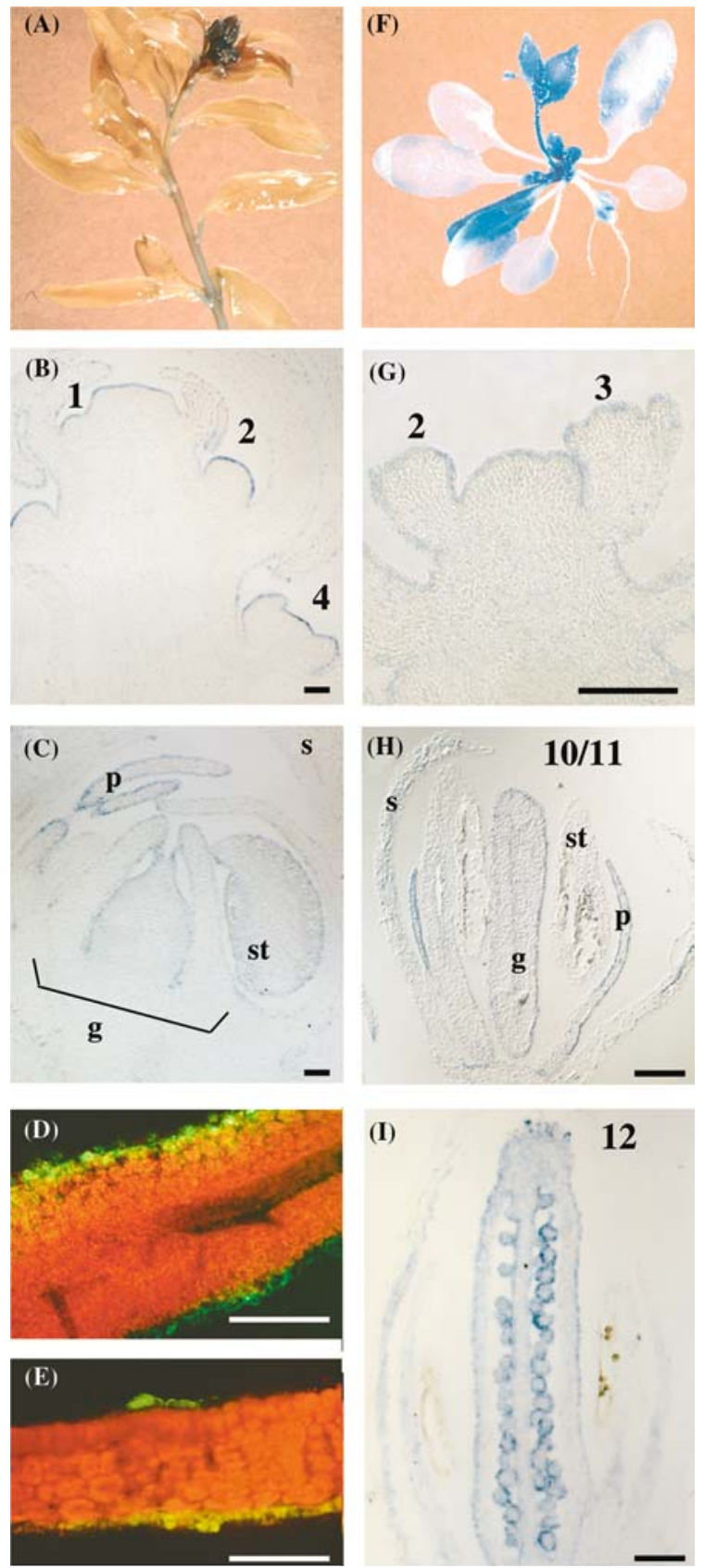
Figure 7. Expression of reporter genes under the control of the $F D H$ and $A F I$ promoters in heterologous transgenic plants. Analysis of transgenic $F D H::$ GUS plants of Antirrhinum (AD) and transgenic $A F I::$ GFP (E) and $A F I::$ GUS (F-I) plants of Arabidopsis. Panels $\mathrm{G}$ and $\mathrm{H}$ show Nomarski images. Numbers indicate floral developmental stages (Smyth et al., 1990; Zachgo et al., 1995). (A). Shoot of a transgenic $F D H::$ GUS plant stained with X-Gluc; compare to shoots of AFI::GUS transgenic plants in Figure 5J, K (B, C). In situ hybridization analysis with the GUS probe reveals specific signals in the protodermis and the epidermis in inflorescences of Antirrhinum $F D H::$ GUS plants. Note the similarity to the Antirrhinum plants in Figure 5A, B (D). Histochemical staining of $F D H::$ GUS transgenic plants using ImaGene Green. Fluorescent signals of an ImaGene Green hydrolysis product (green color) and the background fluorescence (red color) were examined using CLS microscopy.(E). CLS analysis of a leaf section of a transgenic Arabidopsis AFI::GFP plant. (F). Transgenic AFI::GUS plant of Arabidopsis stained with XGluc. (G-I). Transgenic AFI::GUS plants of Arabidopsis analyzed by in situ hybridization with a GUS probe. Note specific signals in the protodermis and the epidermis of floral organs. Weaker signals can be seen in the epidermis of inner carpel walls and the septum, while ovule and abaxial carpel epidermal cells exhibit stronger signals (I). Size bars are $100 \mu \mathrm{m}$.

Interestingly, when ImaGene Green was used as a substrate for histochemical staining of these plants, additional signals were frequently observed in vascular bundles (data not shown), while the staining in leaves was confined to the epidermis (Figure 7D). We attribute the background signal to rapid hydrolysis of the ImaGene Green substrate in vascular cells. Expression of the $A F I$ promoter in Arabidopsis was tested by using the GUS and GFP reporter genes in independent $T_{0}$ transgenic plants. Similarly to the $F D H$ promoter, the $A F I$ promoter appeared to be specific for the epidermis of younger tissues of transgenic plants (Figure 7E, G). Its pattern of expression in flowers was also similar to that of the $F D H$ promoter, although somewhat weaker (Figure $7 \mathrm{H}$ ). Inner walls of carpels and the ovary septum displayed reduced expression of GUS (Figure 7I) and GFP (data not shown) compared to outer carpel walls. With regard to expression patterns, the 470-bp AFI promoter fragment was essentially identical to a larger promoter fragment that we used previously to express floral homeotic genes in the epidermis (Efremova et al., 2001). The 470-bp fragment was fully operative in Arabidopsis as in Antirrhinum.

Thus, the two orthologous promoters were each active in the heterologous species, showing identical tissue specific patterns of expression.
The sequences of the AFI and FDH promoters are diverse but share common motifs

Using the COMPARE and PILEUP programs, we found three regions of similarity in the defined promoter fragments (Figure 8). Two of these similarity boxes, OB1 (orphan box1) and OB2 (orphan box2), contain putative binding sites for MYB transcription factors as predicted by the TFSEARCH program (http://pdap1.trc.rwcp.or.jp/research/db/TFSEARCH. html). A yeast one-hybrid screening of cDNA libraries of Arabidopsis and Antirrhinum is under way in order to identify particular proteins binding to all of these motifs.

\section{Discussion}

FDH and AFI represent functional orthologous epidermis-specific genes in Arabidopsis and Antirrhinum

Three lines of evidence lead us to consider that $F D H$ and $A F I$ represent a pair of orthologous genes (Fitch, 1970). Firstly, no other genes were isolated from an Antirrhinum cDNA library when the $F D H$ probe was used for screening; accordingly, the $A F I$ sequence is unique in the genome, as confirmed by DNA blot analysis (data not shown) and genomic library screening. Secondly, the predicted sequences of the FDH and AFI proteins show remarkable similarity, and are consistently placed at neighboring positions in the phylogenetic tree of the FAE1 family. Thirdly, their exon-intron organization distinguishes $A F I$ and $F D H$ from the other known members of the FAE1 family, indicating that a progenitor of Arabidopsis and Antirrhinum already had a gene with this specific structure.

$A F I$ and $F D H$ are functionally identical with respect to their expression. In situ hybridization analysis of the expression of $F D H$ in Arabidopsis and $A F I$ in Antirrhinum demonstrated that both genes are epidermis-specific and confined to rapidly growing portions of vegetative organs and inflorescences. Promoters of both genes manifested down-regulation in the ovary septum epidermis when they were expressed in Arabidopsis.

In the complementation studies, fertility was restored and organ fusions were averted in $f d h$ mutants expressing the $F D H:: A F I$ transgene. This shows that cellular functions of these proteins are 
essentially identical. The similarity of $F D H$ and $A F I$ makes it likely that these genes play comparable roles in establishing the barrier function of the epidermis. Indeed, chloroacetamides induced fiddlehead phenotypes in Arabidopsis and Antirrhinum, suggesting that afi organ fusion mutants can be identified and characterized to fully test this assumption.

\section{FDH-like genes may not function efficiently in seeds}

The seed-specific FAE1 gene has been shown to be enzymatically active when ectopically expressed from a constitutive promoter (Millar et al., 1998). Therefore, it was rather unexpected to find the $40 \%$ reduction of fatty acids in oil when the epidermis-specific $F D H$ gene was misexpressed in seeds of the FAE1::FDH transgenic plants. Although, the results suggest that FDH may be capable of elongating VLCFAs, in particular C16 fatty acids, it has to be concluded that its ability to elongate fatty acids in seeds is very limited. The low activity or inactivity of FDH in seeds could be due to lacking appropriate fatty acid substrates or protein-protein interactions required for assembly of FDH into the seed-specific elongation protein heterocomplex. Likewise, 11 (including $F D H$ ) out of 17 genes, members of the FAE1 gene family, have been shown to be inactive in yeast while the rest genes appeared to function as fatty acid elongases (Trenkamp et al., 2004).

\section{FDH-like genes may play a general role in} determining whether apposed epidermal cell surfaces interact

The use of GFP allowed us to investigate FDH promoter activity in a number of organs and cell types in Arabidopsis. Assuming that $F D H$ plays a role in the biosynthesis of cutin monomers or/and cross-linking of the cuticular layer of cell walls, one can expect it to be active in rapidly growing parts of the shoot, where cells fabricate the cuticle. $F D H$ expression was indeed observed in the expected epidermal cells, with some striking exceptions, represented by the ovary septum and the funiculus, where expression was greatly reduced as compared to the epidermis on abaxial and adaxial sides of carpels. Assuming that the rates of growth of the carpel wall and the septum along the longitudinal axis are identical, lower levels of expression of $F D H$ in the septum epidermis (Figure $6 \mathrm{E}-\mathrm{J}$ ) could result in a relative deficiency of cuticle material. The phenotypic effects of this down-regulation may be effectively comparable to those observed in knock-out $f d h$ mutants, which display epidermal fusions and permit pollen to grow when deposited on leaves (Lolle et al., 1992; Lolle and Cheung, 1993). At the level of transcription, the down-regulation of FDH alone could, therefore, promote the postgenital fusion of carpels and/or interactions between the receptive septum and pollen tubes. This is in agreement with the finding that the epidermis of young floral organs supports pollen growth and the proposal that the $f d h$ mutation acts by maintaining the floral epidermis in an immature state (Kandasamy et al., 1994). Interestingly, down-regulation of $F D H$ in the septum epidermis contrasts with an elevated expression of the homeobox gene MERISTEM LAYER 1 (Lu et al., 1996), which otherwise displays a similar expression pattern to $F D H$ in the protodermis and the epidermis of young floral organs.

The separation of cells constituting the anther walls allows pollen sacs to open and release the

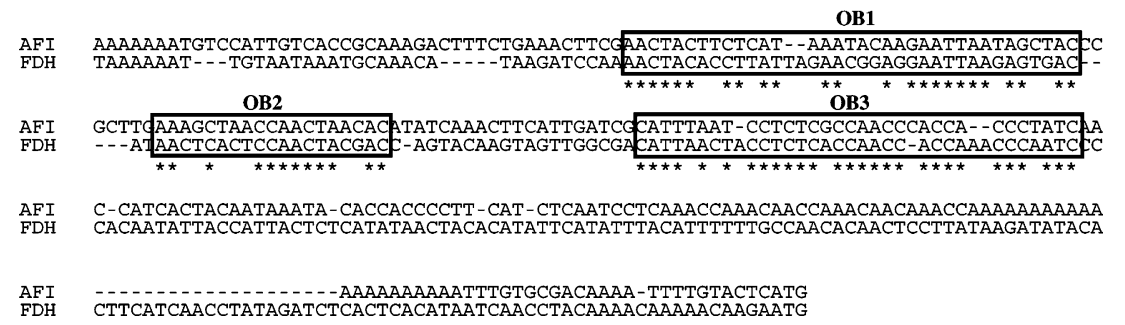

Figure 8. Common sequence motifs in the $F D H$ and $A F I$ promoters. The sequences of the 289-bp fragment of the $F D H$ promoter and the 274-bp fragment of the AFI promoter are shown. Open boxes indicate common sequence motifs (OB1, OB2 and OB3); stars indicate invariant nucleotides. The sequences terminate at their $3^{\prime}$ ends with ATG triplets that correspond to the start codons of the FDH and AFI proteins. The alignment was constructed with the PILEUP program from the Genetics Computer Group (Madison, WI) software package and edited manually. 
pollen. The split appears specifically between stomium cells that are located along the groove between the paired locules. The enhanced expression of $F D H$ that we observed in the stomium region (Figure 6P) is particularly interesting in the light of the ontogeny of the pollen sac wall. Pollen sac walls could be considered as margins of diplophyllous (having two blades) leaf-like organs (Weberling, 1992); accordingly, stomium cells originate from L1 (Goldberg et al., 1993). Therefore, it is conceivable that $F D H$ is required for proper cell separation and, conversely, that suppression of its function results in tissue fusion. Due to the nearly complete sterility of $f d h$ mutants caused by extreme floral-organ fusions, it is very difficult to determine whether the $f d h$ mutant displays delayed anther dehiscence. Several dehiscence mutants are available in Arabidopsis (Sanders et al., 1999) that could be helpful in establishing the role of the $F D H$ gene in the process of cell separation within the stomium. Like $F D H$, the anther dehiscence genes that have so far been identified molecularly, DEFECTIVE IN ANTHER DEHISCENCE 1 (DADI) (Ishiguro et al., 2001), DELAYED DEHISCENCE 1 (Sanders et al., 2000) and OPR3 (Stintzi and Browse, 2000), all encode enzymes of lipid metabolism.

The coordination of the $F D H$ gene expression with the developmental potency of cells to separating and fusing raises intriguing questions of how this regulation can be achieved and whether it is unique to Arabidopsis.

\section{Differences in floral anatomy can account for the differences in FDH and AFI expression in the gynoecium}

The anatomy of the gynoecium, and in particular the origins of the ovary septum, are markedly different between Arabidopsis and Antirrhinum. In Arabidopsis and many other Brassica species, the ovary septum is a so-called false septum that, ontogenetically, does not represent the lateral walls of two carpels but rather is formed by 'intercalary elongation of the sides of the carpel between the outermost carpel margin and the submarginal placentas' (Weberling, 1992) with subsequent postgenital fusion, which occurs longitudinally along the whole pistil. During pollination, the ovary septum and the funiculi establish a surface contact with pollen tubes after they emerge out of transmitting tissue; their pollen-supportive function appears to be important for effective pollen guidance (Lennon et al., 1998). Formation of a false septum is restricted to Brassicaceae; in many other families, including Scrophulariaceae, to which Antirrhinum belongs, ovules reside on the greatly proliferated placenta, which constitutes a septum that is thought to be ontogenically derived from the lateral walls of carpels. At floral stages 5-6 in Antirrhinum, a protruding dome of placenta tissue can be seen in the center of the growing carpel cylinder (Figure 5B, N, O). At later stages, postgenital fusion between the placenta and inner carpel walls results in the formation of a short apical septum. The apical regions of carpels fuse postgenitally to enclose the ovary, and the fusion proceeds to the emerging style and the stigma of the pistil. Finally, a transmitting tissue develops in the apical septum and the style, providing a path for growing pollen tubes. The major stages of gynoecium development in Antirrhinum have been documented in detail (Awasthi et al., 1984; Waites and Hudson, 1995; Zachgo et al., 1995).

It is conceivable that the differences in ontogeny of the ovary septum between Arabidopsis and Antirrhinum are reflected in the distinct expression patterns of orthologous genes. Indeed, our results demonstrate that, in contrast to $F D H$ in Arabidopsis (Figure 6E-J), AFI in Antirrhinum does not show down-regulation in the epidermis of the ovary septum (Figure 5G-I). It is important to note in this context that the $A F I$ promoter does show reduced expression in the ovary septum in transgenic Arabidopsis plants, just like the endogenous FDH promoter (Figure 6I). This suggests that the differences between $F D H$ and $A F I$ expression patterns in the pistil of Arabidopsis and Antirrhinum reflect the distinctive floral anatomies in these species.

\section{FDH and AFI genes can distinguish between epidermal and L1-derived non-epidermal cells}

It is known that not all $\mathrm{L} 1$ cells contribute to the epidermis of the shoot (Satina, 1944). Particularly in Arabidopsis, adaxial L1 cells at carpel medial ridges give rise to parenchymatous cells in the ovary septum after postgenital fusion (Sessions and Zambryski, 1995), and carpel adaxial L1 cells 
form transmitting tissue in the style of a pistil (Jenik and Irish, 2000). Similarly in Antirrhinum, petal margins contain L1-derived parenchymatous and epidermal cells (Perbal et al., 1996). We found that in both species, the expression of $F D H$ and $A F I$ is restricted to the protodermis and the epidermis, and ceases as epidermal cells change their tissue identity and redifferentiate into parenchyma (Figures 5C, and 6I). It is not surprising that $F D H$ and $A F I$ expression does not follow the L1 cell lineage but rather the epidermal status of a cell, if they in fact determine specific features of the epidermis. Genes which are expressed in all L1 cells in a lineage-specific fashion remain to be identified. It would be interesting to see whether this distinction is respected by other genes expressed in the protodermis, particularly, by PROTODERMAL FACTORl (Abe et al., 1999) and the homeobox gene MERISTEM LAYER 1, which was suggested to play a role in establishing L1 in the embryo $(\mathrm{Lu}$ et al., 1996; Sessions et al., 1999).

\section{Acknowledgments}

We thank Hans Sommer for the genomic and cDNA libraries of Antirrhinum and Arabidopsis; Christine Perbal for providing L1 def periclinal chimera material; Aldona Ratajek-Kuhn for excellent care of the plants. We are especially grateful to Paul Hardy for correcting the manuscript. The work was in part supported by a SFB 572 Grant from the Deutsche Forschungsgemeinschaft to Z. Sch.-S. and by the Fonds der Chemischen Industrie to L.S.

\section{References}

Abe, M., Takahashi, T. and Komeda, Y. 1999. Cloning and characterization of an L1 layer-specific gene in Arabidopsis thaliana. Plant Cell Physiol. 40: 571-580.

Awasthi, D.K., Kumar, V. and Murty, Y.S. 1984. Flower development in Antirrhinum majus L. (Scrophulariaceae) with a comment upon corolla tube formation. Bot. Mag. Tokyo 97: 13-22.

Baud, S., Bellec, Y., Miquel, M., Bellini, C., Caboche, M., Lepiniec, L., Faure, J.-D. and Rochat, C. 2004. Gurke and pasticcino3 mutants affected in embryo development are impaired in acetyl-CoA carboxylase. EMBO Rep. 5: 515-520.

Becker, D., Kemper, E., Schell, J. and Masterson, R. 1992. New plant binary vectors with selectable markers located proximal to the left T-DNA border. Plant Mol. Biol. 20: 1195-1197.
Boeger, P., Matthes, B. and Schmalfuss, J. 2000. Towards the primary target of chloroacetamides - new findings pave the way. Pest Manage. Sci. 56: 497-508.

Chen, X., Goodwin, S.M., Boroff, V.L., Liu, X. and Jenks, M.A. 2003. Cloning and characterization of the $W A X 2$ gene of Arabidopsis involved in cuticle membrane and wax production. Plant Cell 15: 1170-1185.

Duret, L. and Bucher, P. 1997. Searching for regulatory elements in human noncoding sequences. Curr. Opin. Struct. Biol. 7: 399-406.

Efremova, N., Perbal, M.-C., Yephremov, A., Hofmann, W.A., Saedler, H. and Schwarz-Sommer, Z. 2001. Epidermal control of floral organ identity by class B homeotic genes in Antirrhinum and Arabidopsis. Development 128: 2661-2671.

Fitch, W.M. 1970. Distinguishing homologous from analogous proteins. Syst. Zool. 19: 99-113.

Goldberg, R.B., Beals, T.P. and Sanders, P.M. 1993. Anther development: Basic principles and practical applications. Plant Cell 5: 1217-1229.

Haseloff, J. and Siemering, K.R. 1998. The uses of green fluorescent protein in plants. In: M. Chalfie and S. Kain (Eds), Green Fluorescent Protein: Properties, Applications, and Protocols, John Wiley and Sons Ltd., Chichester, England, pp. 191-220.

Heidmann, I., Efremova, N., Saedler, H. and Schwarz-Sommer, Z. 1998. A protocol for transformation and regeneration of Antirrhinum majus. Plant J. 13: 723-728..

Huelskamp, M. and Schnittger, A. 1998. Spatial regulation of trichome formation in Arabidopsis thaliana. Semin. Cell Devel. Biol. 9: 213-220.

Ishiguro, S., Kawai-oda, A., Ueda, J., Nishida, I. and Okada, K. 2001. The defective in anther dehiscencel gene encodes a novel phospholipase A1 catalyzing the initial step of jasmonic acid biosynthesis, which synchronizes pollen maturation, anther dehiscence, and flower opening in Arabidopsis. Plant Cell 13: 2191-2209.

James, D.W., Lim, E., Keller, J., Plooy, I., Ralston, E. and Dooner, H.K. 1995. Directed tagging of the Arabidopsis FATTY ACID ELONGATION1 (FAE1) gene with the maize transposon Activator. Plant Cell 7: 309-319.

Jefferson, R.A., Kavanagh, T.A. and Bevan, M.W. 1987. GUS fusions: $\beta$-glucuronidase as a sensitive and versatile gene fusion marker in higher plants. EMBO J. 6: 3901-3908.

Jenik, P.D. and Irish, V.F. 2000. Regulation of cell proliferation patterns by homeotic genes during Arabidopsis floral development. Development 127: 1267-1276.

Kandasamy, M.K., Nasrallah, J.B. and Nasrallah, M.E. 1994. Pollen-pistil interactions and developmental regulation of pollen tube growth in Arabidopsis. Development 120: 3405-3418.

Klimyuk, V., Carroll, B., Thomas, C.M. and Jones, J.D. 1993. Alkali treatment for rapid preparation of plant material for reliable PCR analysis. Plant J. 3: 493-494.

Kurata, T., Kawabata-Awai, C., Sakuradani, E., Shimizu, S., Okada, K. and Wada, T. 2003. The YORE-YORE gene regulates multiple aspects of epidermal cell differentiation in Arabidopsis. Plant J. 36: 55-66.

Lechelt-Kunze, C., Meissner, R.C., Drewes, M. and Tietjen, K. 2003. Flufenacet herbicide treatment phenocopies the fiddlehead mutant in Arabidopsis thaliana. Pest Manage. Sci. 59: 847-856.

Lennon, K.A., Roy, S., Hepler, P.K. and Lord, E.M. 1998. The structure of the transmitting tissue of Arabidopsis thaliana 
(L.) and the path of pollen tube growth. Sex. Plant Reprod. 11: 49-59.

Lolle, S.J., Berlyn, G.P., Engstrom, E.M., Krolikowski, K.A., Reiter, W.D. and Pruitt, R. E. 1997. Developmental regulation of cell interactions in the Arabidopsis fiddlehead-1 mutant: a role for the epidermal cell wall and cuticle. Developmental Biol. 189: 311-21.

Lolle, S. J. and Cheung, A. Y. 1993. Promiscuous germination and growth of wildtype pollen from Arabidopsis and related species on the shoot of the Arabidopsis mutant fiddlehead. Developmental Biol. 155: 250-258.

Lolle, S. J., Cheung, A.y. and Sussex, I.M. 1992. Fiddlehead: an Arabidopsis mutant constitutively expressing an organ fusion program that involves interactions between epidermal cells. Developmental Biol. 152: 383-392.

Lu, P., Porat, R., Nadeau, J.A. and O'Neill, D. 1996. Identification of a meristem L1 layer-specific gene in Arabidopsis that is expressed during embryonic pattern formation and defines a new class of homeobox genes. Plant Cell 8: 2155-2168.

Millar, A.A., Wrischer, M. and Kunst, L. 1998. Accumulation of very-long-chain fatty acids in membrane glycerolipids is associated with dramatic alterations in plant morphology. Plant Cell 10: 1889-1902.

Perbal, M.C., Haughn, G., Saedler, H. and Schwarz Sommer, Z. 1996. Non-cell-autonomous function of the Antirrhinum floral homeotic proteins DEFICIENS and GLOBOSA is exerted by their polar cell-to-cell trafficking. Development 122: 3433-3441.

Pruitt, R.E., Vielle-Calzada, J.P., Ploense, S.E., Grossniklaus, U. and Lolle, S.J. 2000. FIDDLEHEAD, a gene required to suppress epidermal cell interactions in Arabidopsis, encodes a putative lipid biosynthetic enzyme. Proc. Natl. Acad. Sci. USA 97: 1311-1316.

Rossak, M., Smith, M. and Kunst, L. 2001. Expression of the $F A E 1$ gene and FAE1 promoter activity in developing seeds of Arabidopsis thaliana. Plant Mol. Biol. 46: 717-725.

Sanders, P.M., Bui, A Q., Weterings, K., McIntire, K.N., Hsu, Y.-C., Lee, P.Y., Truong, M.T., Beals, T. P. and Goldberg, R. B. 1999. Anther developmental defects in Arabidopsis thaliana male-sterile mutants. Sex. Plant Reprod. 11: 297-322.

Sanders, P.M., Lee Pei, Y., Biesgen, C., Boone, J.D., Beals, T.P., Weiler, E.W. and Goldberg, R.B. 2000. The Arabidopsis DELA YED DEHISCENCE1 gene encodes an enzyme in the jasmonic acid synthesis pathway. Plant Cell 12: 1041-1061.

Satina, S. 1944. Periclinal chimeras in Datura in relation to development and structure (A) of the style and stigma (B) of calyx and corolla. Am. J. Bot. 31: 493-502.
Sessions, R.A. and Zambryski, P.C. 1995. Arabidopsis gynoecium structure in the wild type and in ettin mutants. Development 121: 1519-1532.

Sessions, A., Weigel, D. and Yanofsky, M.F. 1999. The Arabidopsis thaliana MERISTEM LAYER 1 promoter specifies epidermal expression in meristems and young primordia. Plant J. 20: 259-263.

Smyth, D.R., Bowman, J.L. and Meyerowitz, E.M. 1990. Early flower development in Arabidopsis. Plant Cell 2: 755-768.

Stintzi, A., and Browse, J. 2000. The Arabidopsis male-sterile mutant, opr3, lacks the 12-oxophytodienoic acid reductase required for jasmonate synthesis. Proc. Natl. Acad. Sci. USA 97: 10625-10630.

Trenkamp, S., Martin, W. and Tietjen, K. 2004. Specific and differential inhibition of very-long-chain fatty acid elongases from Arabidopsis thaliana by different herbicides. Proc. Natl. Acad. Sci. USA 101: 11903-11908.

Vancanneyt, G., Schmidt, R., O'Connor, S.A., Willmitzer, L. and Rocha Sosa, M. 1990. Construction of an introncontaining marker gene splicing of the intron in transgenic plants and its use in monitoring early events in Agrobacterium-mediated plant transformation. Mol. Gen. Genet. 220: 245-250.

Van Den Berg, C., Willemsen, V., Hendriks, G., Weisbeek, P. and Scheres, B. 1997. Short-range control of cell differentiation in the Arabidopsis root meristem. Nature 390: 287-289.

Waites, R. and Hudson, A. 1995. PHANTASTICA: a gene required for dorsoventrality of leaves in Antirrhinum majus. Development 121: 2143-2154.

Weberling, F. 1992. Morphology of Flowers and Inflorescences. Cambridge Univ. Press, Cambridge, UK, N.Y.

Wellesen, K., Durst, F., Pinot, F., Benveniste, I., Nettesheim, K., Wisman E., Steiner-Lange, S., Saedler, H. and Yephremov, A. 2001. Functional analysis of the LACERA$T A$ gene of Arabidopsis provides evidence for different roles of fatty acid $\omega$-hydroxylation in development. Proc. Natl. Acad. Sci. USA 98: 9694-9699.

Yephremov, A., Wisman, E., Huijser, P., Huijser, C., Wellesen, K. and Saedler, H. 1999. Characterization of the FIDDLE$H E A D$ gene reveals a link between adhesion response and cell differentiation in the epidermis. Plant Cell 11: 2187-2201.

Zachgo, S., de Andrade Silva, E., Motte, P., Troebner, W. Saedler, H. and Schwarz-Sommer, Z. 1995. Functional analysis of the Antirrhinum floral homeotic DEFICIENS gene in vivo and in vitro by using a temperature-sensitive mutant. Development 121: 2861-2875. 